Supporting information

\title{
Efficient Organic Solar Cells Enabled by Chlorinated Nonplanar Small Molecules
}

Baofeng Zhao, ${ }^{\mathrm{a}, \dagger}$ Haimei Wu, ${ }^{\mathrm{a}, \dagger}$ Jin Su, ${ }^{\mathrm{a}}$ Liuchang Wang, ${ }^{\mathrm{b}}$ Weiping Wang, ${ }^{\mathrm{a}}$ Zhiyuan Cong, ${ }^{\mathrm{a}}$

$$
\text { Chao Gao }{ }^{\mathrm{a}, *}
$$

a State Key Laboratory of Fluorine \& Nitrogen Chemicals, Xi'an Modern Chemistry

Research Institute, NO.168 of East Zhangba Road, Xi' an, 710065, China.

${ }^{b}$ School of Chemical Engineering, Xi'an University, No. 168 of

South Taibai Road, Xi’an, 710065, China.

${ }^{\dagger}$ B. Zhao and H. Wu contributed equally to this work.

*Corresponding author, E-mail: chaogao1974@hotmail.com. 


\section{Content of the supporting information}

\begin{tabular}{|c|c|}
\hline Content & Page \\
\hline Material synthesis and characterization. & S3-S4 \\
\hline Fabrication and characterization of the photovoltaic cells & S4 \\
\hline Carrier mobility measurement. & S4-S5 \\
\hline Figure S1-S4. ${ }^{1} \mathrm{H}$ NMR and ${ }^{13} \mathrm{C}$ NMR spectra of the i-IEICO-2Cl and i-IEICO-4Cl. & S6-S7 \\
\hline Figure S5. Thermalgravimetric analysis curves of the two acceptors. & S8 \\
\hline Figure S6. CV plot of J52 film. & S8 \\
\hline $\begin{array}{l}\text { Figure S7. } J^{1 / 2} \text { vs V plots: J52:i-IEICO-2CI and J52:i-IEICO-4CI hole-only and } \\
\text { electron-only devices }\end{array}$ & S8 \\
\hline Figure S8. Structure of i-IEICO-2Cl-30\%. & S9 \\
\hline 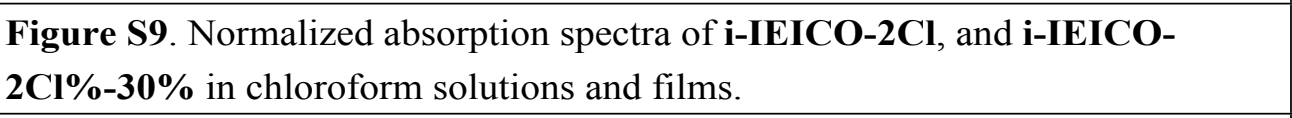 & S9 \\
\hline $\begin{array}{l}\text { Figure S10. The } J-V \text { characteristics of the J52: i-IEICO-2CI and J52: i-IEICO- } \\
\text { 2Cl-30\% based solar cells. }\end{array}$ & S9 \\
\hline $\begin{array}{l}\text { Figure S11. TEM images of J52: i-IEICO-2Cl and J52: i-IEICO-4Cl blend films with } \\
\text { scale-plates of } 100 \text { and } 50 \mathrm{~nm} .\end{array}$ & S10 \\
\hline Figure S12. XRD plots of J52:i-IEICO-2CI and J52:i-IEICO-4CI blend films. & S10 \\
\hline Table S1. Calculations of total energy and their geometries of the four isomers. & S11-12 \\
\hline $\begin{array}{l}\text { Table S2. Calculated molecular energy levels of three isomers at their optimized } \\
\text { geometry from the DFT at B3LYP/6-31G(d,p) level. }\end{array}$ & S12-13 \\
\hline $\begin{array}{l}\text { Table S3. Calculated dipole moments of three isomers at their optimized geometry } \\
\text { from the DFT at B3LYP/6-31G }(\mathrm{d}, \mathrm{p}) \text { level. }\end{array}$ & S13 \\
\hline Table S4. Measurement of the hole and electron mobilities. & S13 \\
\hline Table S5. Photovoltaic parameters of the J52:i-IEICO-2CI-30\%-based device. & $\mathrm{S} 13$ \\
\hline References & S14 \\
\hline
\end{tabular}


Material Synthesis. All chemicals were purchased from J\&K Scientific Ltd. unless noted. The polymer J52 was synthesized through the pathway according to the literature. ${ }^{1}$ Using gel permeation chromatography (GPC) on a PLGPC220 at $150{ }^{\circ} \mathrm{C}$ with 1,2,4-trichlorobenzene as eluent and polystyrene as standard, the weight-average molecular weight $\left(\mathrm{M}_{\mathrm{w}}\right)$ of $\mathrm{J} 52$ is determined as $170 \mathrm{kDa}$ with a polydispersity index (PDI) of 3.2. The two SMAs were synthesized through the route in Scheme 1, in which key intermediate compound $\mathbf{1}$ was obtained according to our previous work. ${ }^{2}$

Synthesis of i-IEICO-2Cl. To a dry $50 \mathrm{ml}$ two-necked bottom round flask, compound $\mathbf{1}$ (277 mg, 0.2 $\mathrm{mmol})$ and $2(228 \mathrm{mg}, 1 \mathrm{mmol})$ were dissolved in dry chloroform $(25 \mathrm{ml})$, pyridine $(1.3 \mathrm{ml})$ was added, and the mixture was refluxed at $65^{\circ} \mathrm{C}$ for $3.5 \mathrm{~h}$, after cooling to the room temperature, the mixture was poured into methanol and filtrated. The residue was purified by column chromatography on silica gel using chloroform as the eluent to afford compound i-IEICO-2CI $(252 \mathrm{mg})$ in a yield of $69.8 \% .{ }^{1} \mathrm{H}$ NMR (500 $\left.\mathrm{MHz}, \mathrm{CDCl}_{3, \delta} \delta\right): 9.13(\mathrm{~s}, 2 \mathrm{H}), 8.57(\mathrm{~s}, 1.52), 8.52(\mathrm{~m}, 0.48 \mathrm{H}), 7.73(\mathrm{~m}, 2 \mathrm{H}), 7.50(\mathrm{~m}, 6 \mathrm{H}), 7.18(\mathrm{~d}, 8 \mathrm{H}, J=8$ Hz), 7.12 (d, 8H, J=8 Hz), 6.89 (s, 2H), 4.13 (m, 4H), 2.59 (t, 8H, J=7.5 Hz), 1.90 (m, 2H), 1.62-1.43 (br, 16H), 1.35-1.30 (m, 32H), 0.97-0.86 (m, 24H). $\left.{ }^{13} \mathrm{C} \mathrm{NMR} \mathrm{(125} \mathrm{MHz,} \mathrm{CDCl}_{3}, \delta\right): 188.16,169.99,159.72$, $158.26,154.70,145.93,142.33,141.48,141.11,140.87,140.38,135.81,135.01,133.76,133.08,128.82$, $127.94,125.26,124.20,118.55,117.71,115.41,114.81,109.15,76.10,67.53,63.34,39.54,35.73,31.86$, 31.49, 30.14, 29.26, 29.09, 23.58, 23.15, 22.74, 14.24, 11.05. Anal. Calcd for $\mathrm{C}_{114} \mathrm{H}_{116} \mathrm{Cl}_{2} \mathrm{~N}_{4} \mathrm{O}_{4} \mathrm{~S}_{4}(\%): \mathrm{C}$ 75.84, H 6.48, N 3.10; Found (\%): C75.74, H 6.483, N 2.73.

Synthesis of i-IEICO-4CI (yield, 72.5\%). The compound was synthesized according to the same route as that for i-IEICO-2CI. ${ }^{1} \mathrm{H}$ NMR (500 MHz, $\mathrm{CDCl}_{3}, \delta$ ): 9.14 (s, 2H), 8.71 (s, 2H), 7.85 (s, 2H), $7.54(\mathrm{~s}, 2 \mathrm{H})$, $7.50(\mathrm{~s}, 2 \mathrm{H}), 8.54(\mathrm{~m}, 2 \mathrm{H}), 7.73(\mathrm{~m}, 2 \mathrm{H}), 7.50(\mathrm{~m}, 6 \mathrm{H}), 7.17$ (d, 8H, J=10 Hz), 7.12 (d, 8H, J=10 Hz), 6.91 (s, 2H), 4.13 (m, 4H), 2.59 (t, 8H, J=7.5 Hz), 1.89 (m, 2H), 1.63-1.46 (br, 16H), 1.34-1.28 (m, 32H), 0.97-0.86 (m, 24H). ${ }^{13} \mathrm{C}$ NMR (125 MHz, $\left.\mathrm{CDCl}_{3}, \delta\right): 186.76,158.61,154.66,149.99,146.37,142.43$, $140.80,138.95,138.50,136.08,128.83,127.93,126.71,124.70,118.33,115.22,114.78,76.11,67.47$, 63.32, 39.40, 35.73, 31.87, 31.49, 30.13, 29.26, 29.08, 23.52, 23.08, 22.74, 14.28, 11.08. Anal. Calcd for $\mathrm{C}_{114} \mathrm{H}_{114} \mathrm{Cl}_{4} \mathrm{~N}_{4} \mathrm{O}_{4} \mathrm{~S}_{4}(\%)$ : C 73.06, H 6.13, N 2.99; Found (\%): C72.72, H 6.03, N 2.66.

\section{Measurement}

Nuclear magnetic resonance spectra (NMR) were measured by Bruker AV 500 spectrometerat in chloroform- $d\left(\mathrm{CDCl}_{3}\right)$ using tetramethylsilane (TMS) as the internal reference at room temperature. The chemical shifts were accounted in ppm related to the singlet of $\mathrm{CDCl}_{3}$ at $7.26 \mathrm{ppm}$ for ${ }^{1} \mathrm{H}$ and $77 \mathrm{ppm}$ for 
${ }^{13} \mathrm{C}$ NMR, respectively. Thermaogravimetric analysis (TGA) of the acceptors was investigated on a Universal V2.6D TA instruments. The absorption spectra were measured by a Perkin Elmer Lambda 750 UV/Vis/NIR spectrometer. The electrochemical cyclic voltammetry of the acceptors was conducted on a $\mathrm{CHI}$ 660D Electrochemical Workstation, using glassy carbon, platinum wire, and $\mathrm{Ag} / \mathrm{Ag}^{+}$electrode as the working electrode, counter electrode, and reference electrode, respectively, in a $0.1 \mathrm{~mol} / \mathrm{L}$ tetrabutylammoniumhexafluorophosphate $\left(\mathrm{Bu}_{4} \mathrm{NPF}_{6}\right)$ acetonitrile solution. The atomic force microscopy (AFM) height images were collected in air under ambient conditions by a MultiMode scanning probe microscope (AFM, Veeco MultiMode V). Transmission electron microscope (TEM) image of the blend film was conducted by Fei Talos F200i microscope.

\section{Fabrication and characterization of the photovoltaic cells}

The devices were fabricated with an inverted architecture of glass/indium tin oxide (ITO) /ZnO/J52:acceptors $/ \mathrm{MoO}_{3} / \mathrm{Al}$. The ITO glass $(15 \Omega / \square)$ were ultrasonicated in detergent, deionized water, acetone, and isopropanol, subsequently. Then the cleaned ITO glass was treated by UV-ozone for $10 \mathrm{~min}$. The $\mathrm{ZnO}$ precursor was spin-casted on the ITO glass and baked at $200^{\circ} \mathrm{C}$ for $1 \mathrm{~h}$ to form the $\mathrm{ZnO}$ layer ( $\sim 40 \mathrm{~nm})$. After cooled to room temperature, the substrates were transferred to a nitrogen-filled glove box. The blend films (80 90 nm) of J52: i-IEICO-2CI or J52-2F: i-IEICO-4CI (the total concentration of 24 $\mathrm{mg} \mathrm{mL} \mathrm{m}^{-1}$ ) were prepared by spin-coating the chlorobenzene (CB) solution of the polymer and $\mathbf{i}-\mathbf{V}-\mathbf{4 F}$ at $2000 \mathrm{rpm}$ for $30 \mathrm{~s}$. Then the blended films were thermally annealed at $150{ }^{\circ} \mathrm{C}$ for $10 \mathrm{~min}$. After that, $\mathrm{MoO}_{3}$ $(\sim 10 \mathrm{~nm})$ layer and $\mathrm{Al}(120 \mathrm{~nm})$ layer were successively vacuum-deposited on the blended films in a high vacuum chamber $\left(2 \times 10^{-4} \mathrm{~Pa}\right)$. Masks made from laser beam cutting technology with a well-defined area size of $0.16 \mathrm{~cm}^{2}$ are attached to define the effective area for accurate measurement. Current density-voltage $(J-V)$ characteristics of the devices were measured on a computer-controlled Keithley 2400 Source Measure unit under 1 sun, air mass 1.5 global (AM 1.5G) illumination provided by a solar simulator (SAN-EI ELECTRIC CO., LTD, XES- 40S3). The illumination intensity used throughout was around $100 \mathrm{~mW} \mathrm{~cm} \mathrm{~cm}^{-2}$, as determined by a mono-crystal silicon reference cell (VLSI Standards Inc) calibrated by the National Renewable Energy Laboratory (NREL). The external quantum efficiencies (EQEs) of the devices were tested by a solar cells spectral response measurement system (QE-R3011, Enlitech Inc.), which was calibrated with a certified silicon detector.

\section{Carrier mobility measurement.}

The space-charge limited current (SCLC) method was used to measure the hole and electron mobility, with 
the devices structures of ITO/PEDOT:PSS (40nm)/Active layer $/ \mathrm{MoO}_{3}(10 \mathrm{~nm}) / \operatorname{Ag}(100 \mathrm{~nm})$ and $\mathrm{ITO} / \mathrm{ZnO}(40 \mathrm{~nm}) /$ Active layer/Ca $(4 \mathrm{~nm}) / \mathrm{Al}(100 \mathrm{~nm})$, respectively. The effective area of the devices is $0.16 \mathrm{~cm}^{2}$. The mobilities were determined by testing the dark current density and fitting the results to a space charge limited form. ${ }^{3}$ SCLC is described as the equation: $J=9 \varepsilon_{0} \varepsilon_{r} \mu_{0} V^{2} / 8 d^{3}$, where $J$ is the current density, $\varepsilon_{0}$ is the permittivity of free space $\left(8.85 \times 10^{-12} \mathrm{~F} \mathrm{~m}^{-1}\right), \varepsilon_{r}$ is the relative permittivity of the materials $(\sim 3.0), \mu_{0}$ is the hole or electron mobility, $V$ is the effective voltage, which can be obtained by substracting the built-in voltage $\left(V_{\mathrm{bi}}\right)$ and the voltage drop $\left(V_{S}\right)$ from the substrate's series resistance from the applied voltage $\left(V_{\text {appl }}\right): V=V_{\text {appl }}-V_{\mathrm{bi}}-V_{s}$. And $d$ is the thickness of the active layer. 

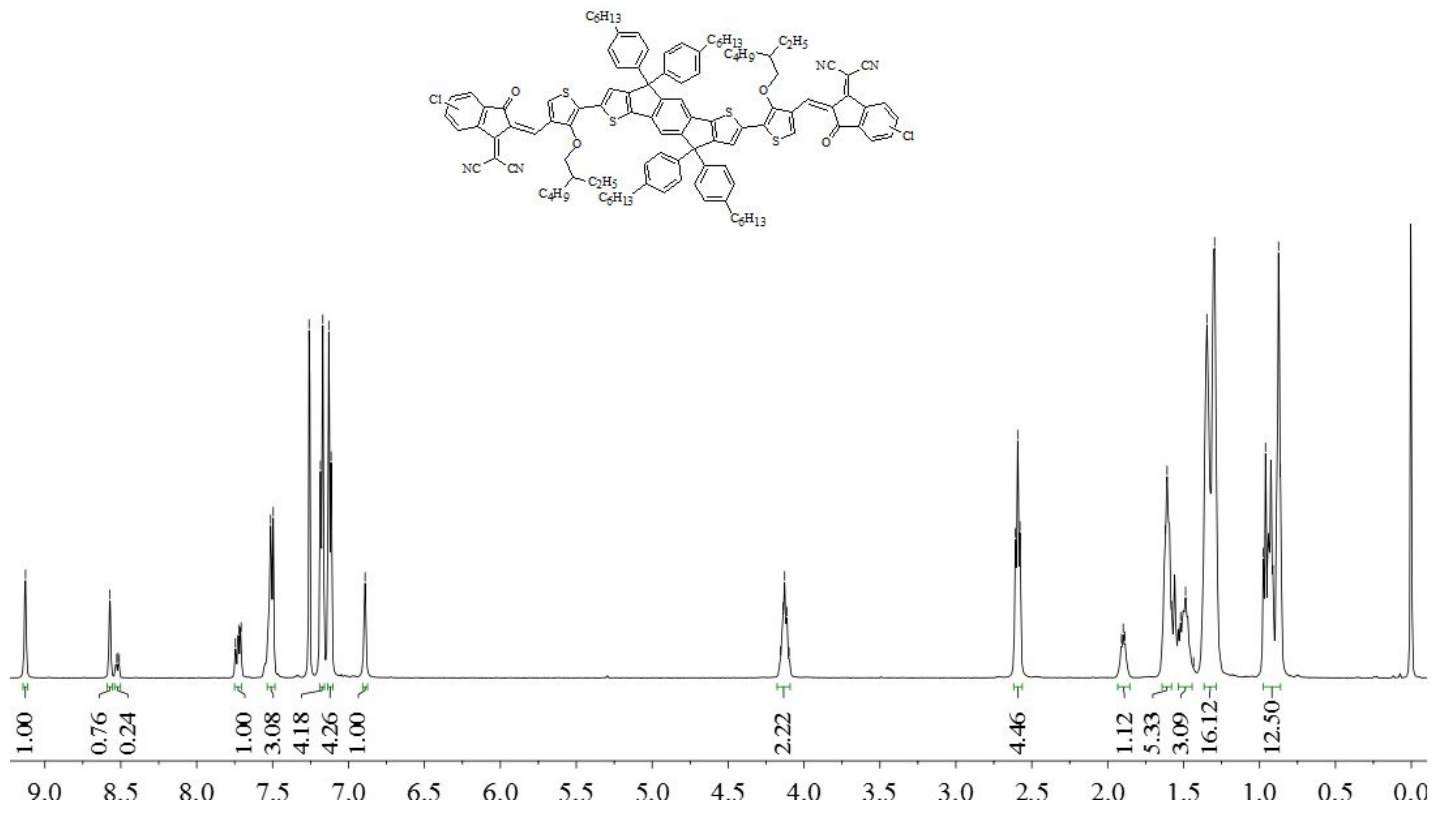

Figure S1. ${ }^{1} \mathrm{H}$ NMR spectrum of i-IEICO-2Cl.

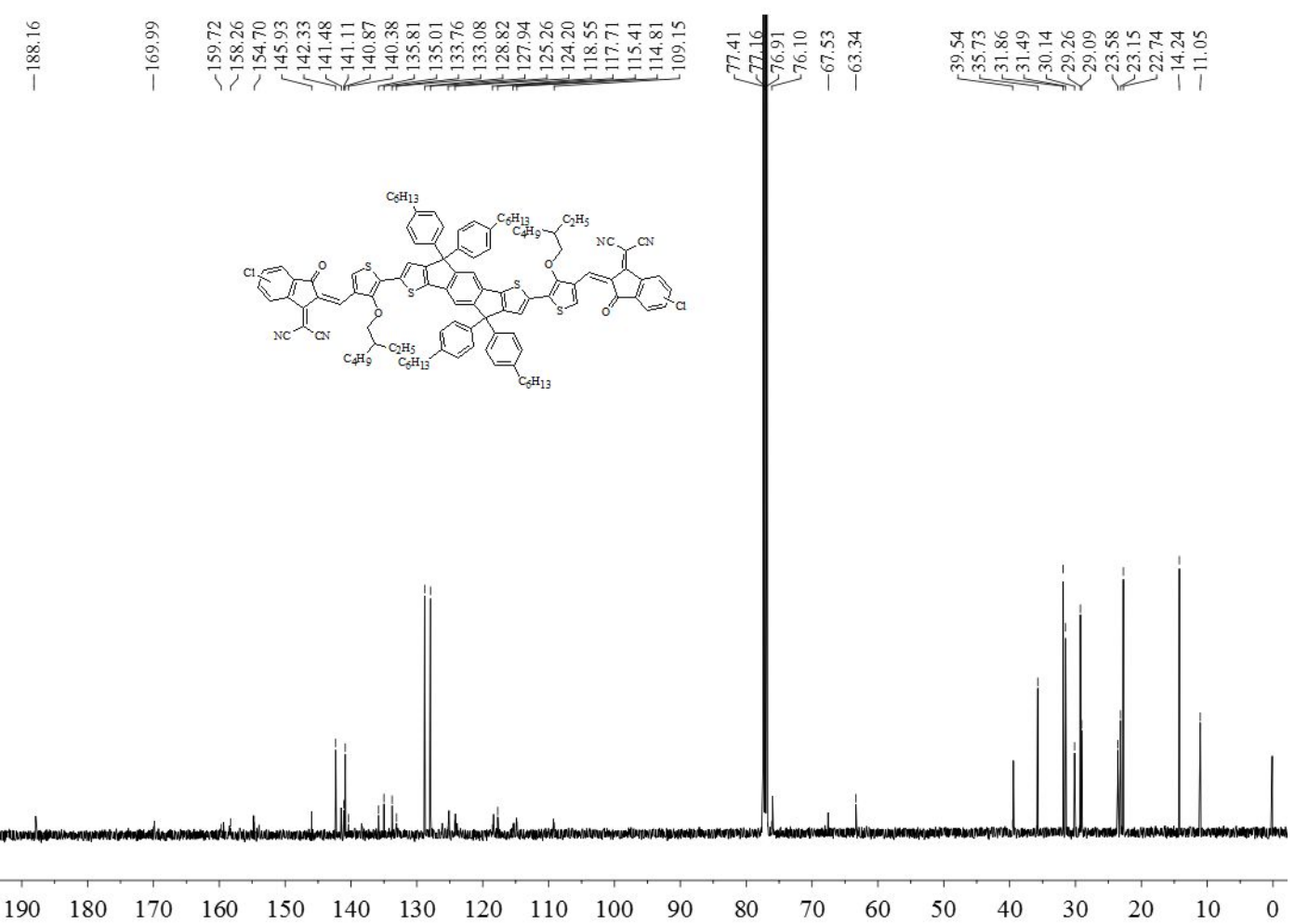

Figure S2. ${ }^{13} \mathrm{C}$ NMR spectrum of i-IEICO-2Cl. 


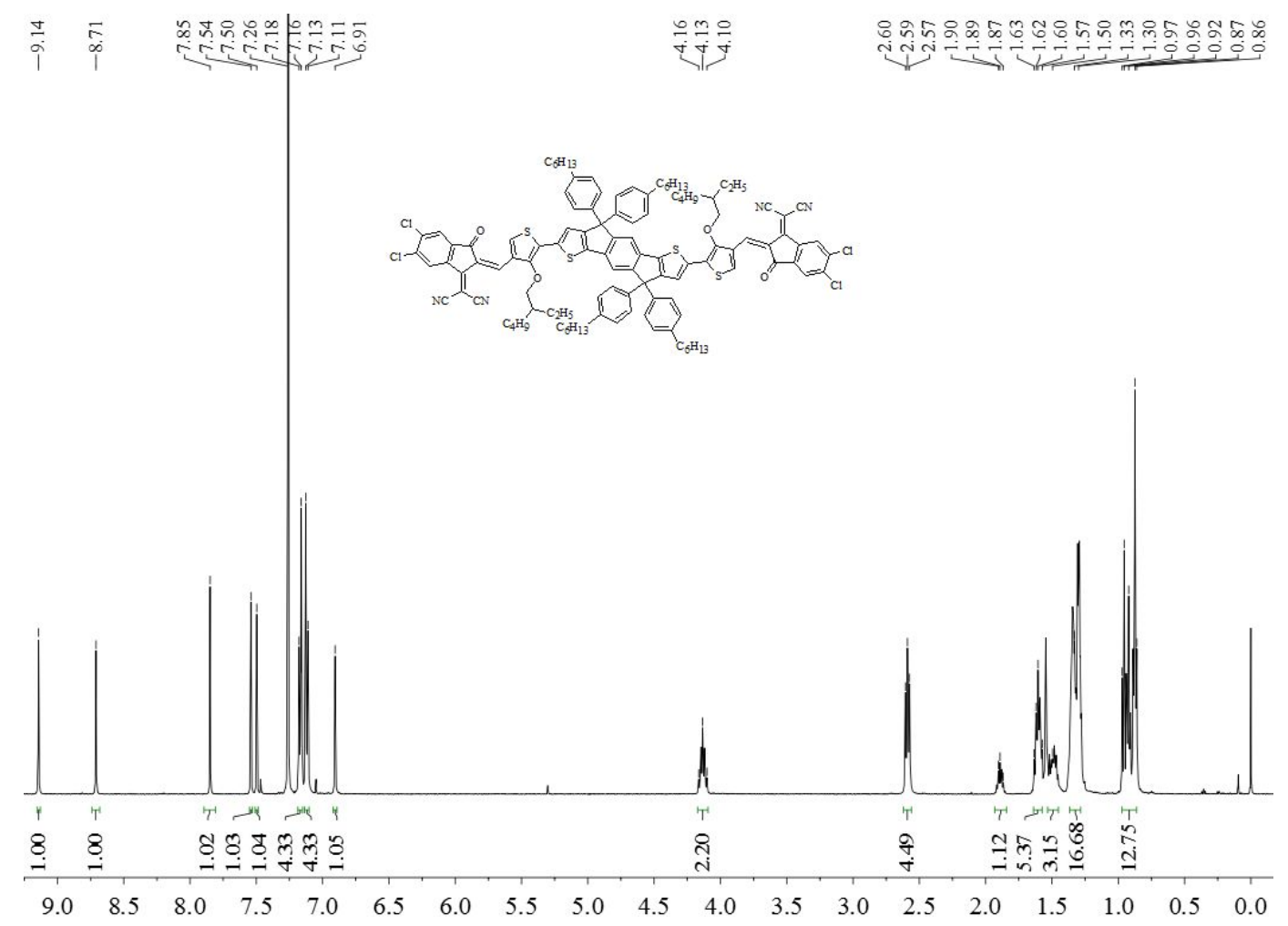

Figure S3. ${ }^{1} \mathrm{H}$ NMR spectrum of i-IEICO-4CI

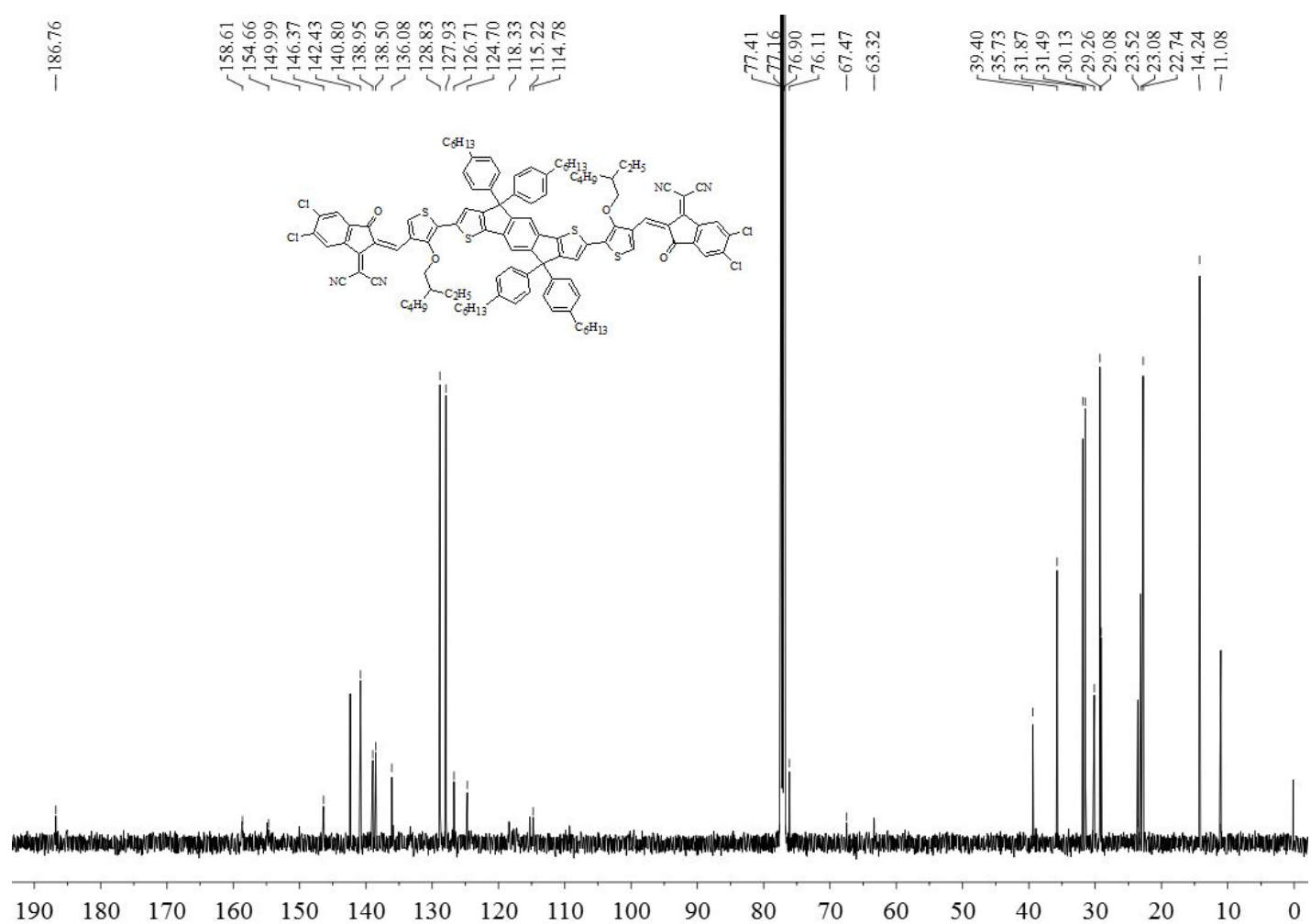

Figure S4. ${ }^{13} \mathrm{C}$ NMR spectrum of i-IEICO-4Cl. 


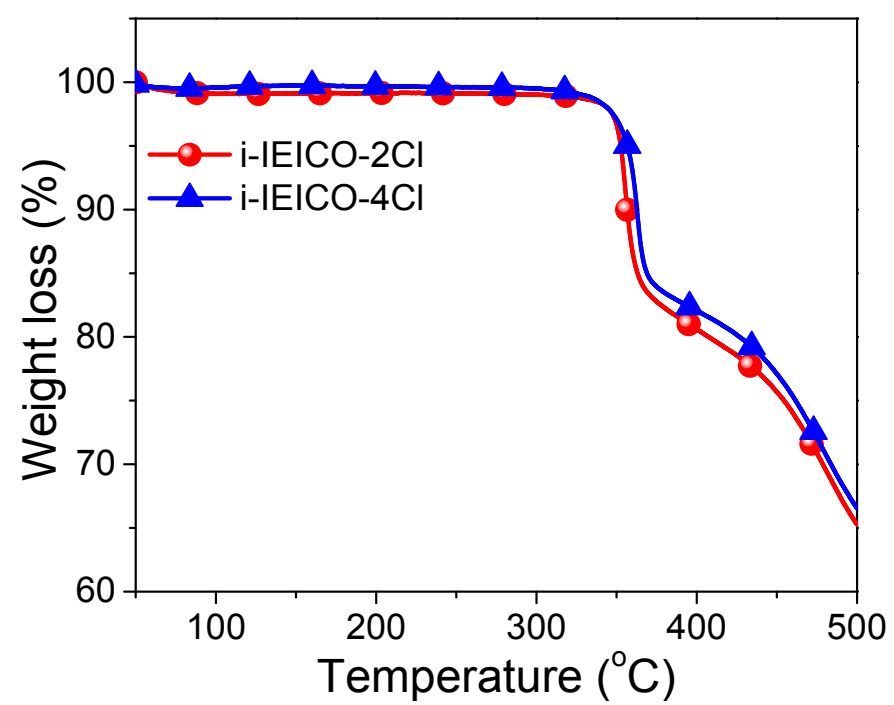

Figure S5. Thermalgravimetric analysis curves of i-IEICO-2CI and i-IEICO-4Cl.

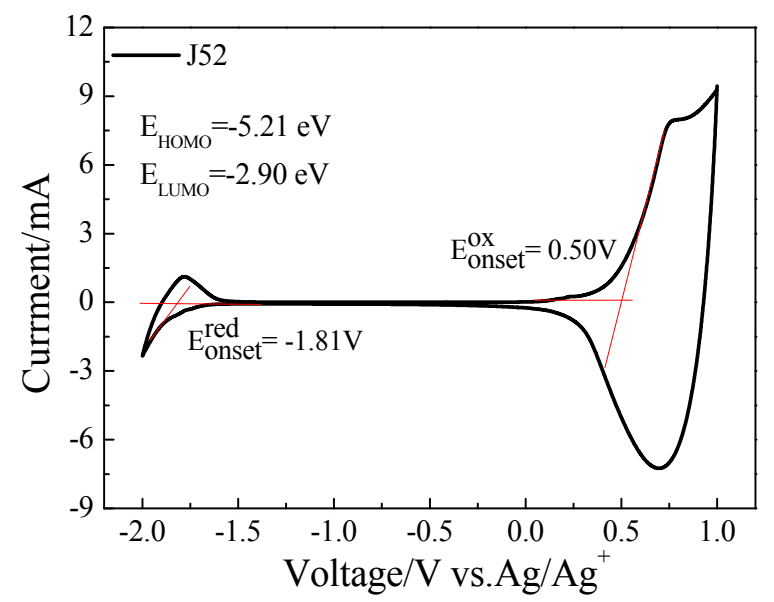

Figure S6. CV plot of J52 film.
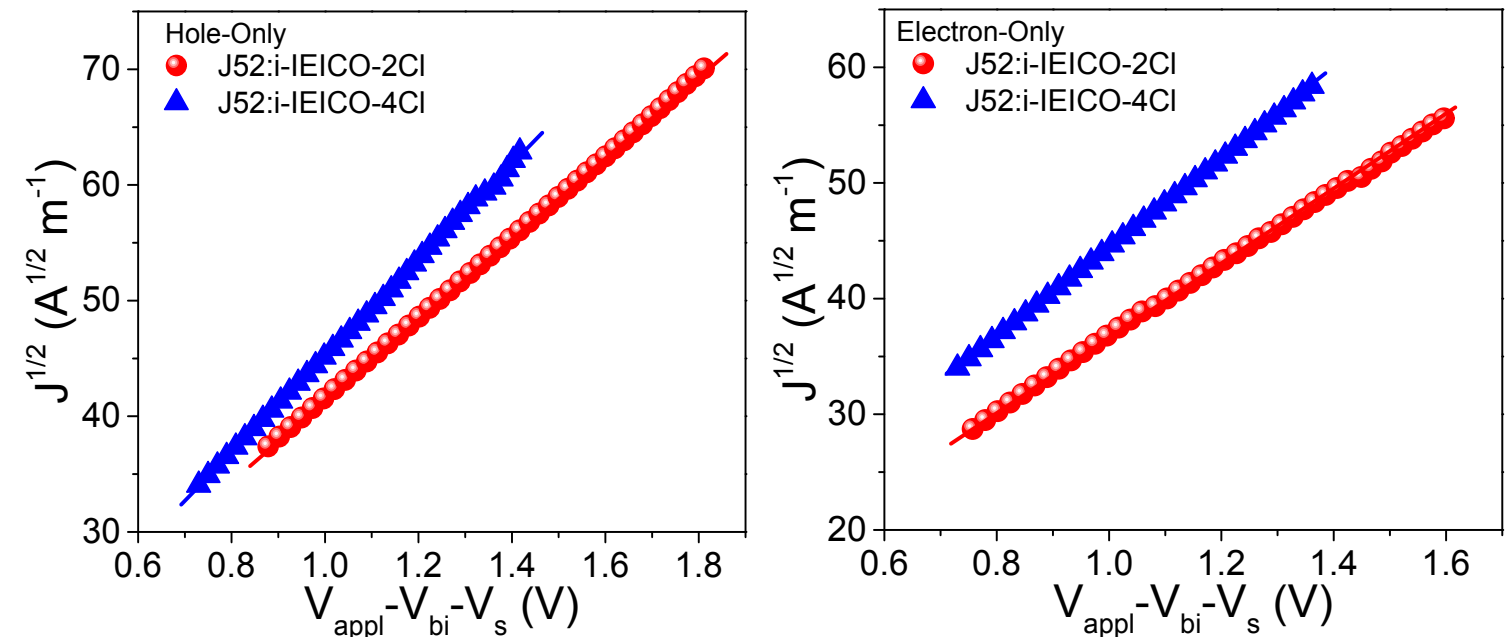

Figure S7. $J^{1 / 2}$ vs V plots: J52:i-IEICO-2CI and J52:i-IEICO-4CI hole-only and electron-only devices. 


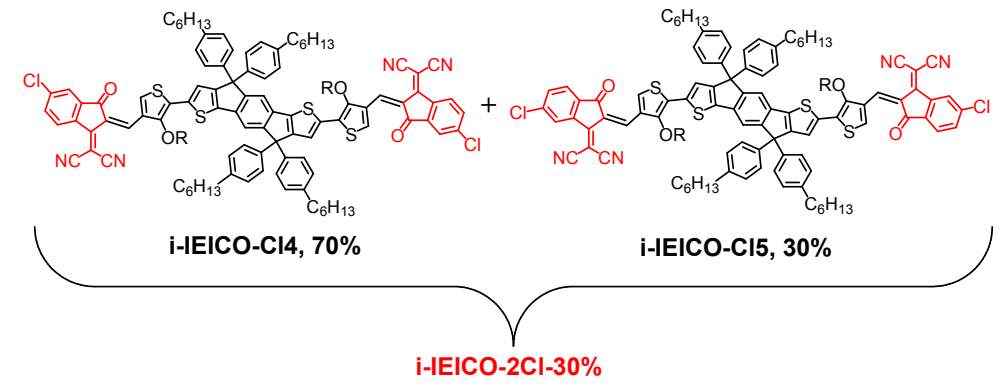

Figure S8. Structure of i-IEICO-2Cl-30\%.

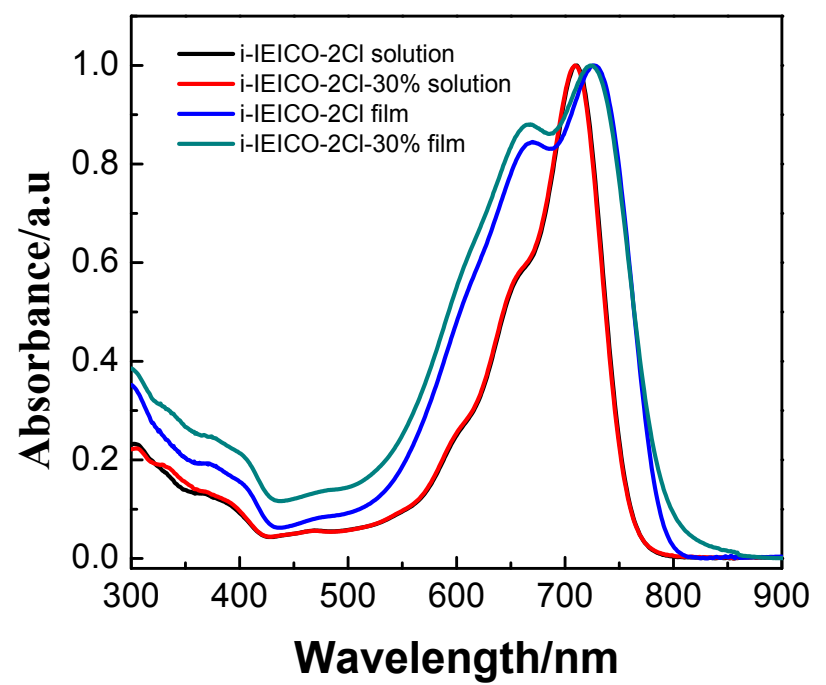

Figure S9. Normalized absorption spectra of i-IEICO-2CI, and i-IEICO-2Cl\%-30\% in chloroform solutions and films.

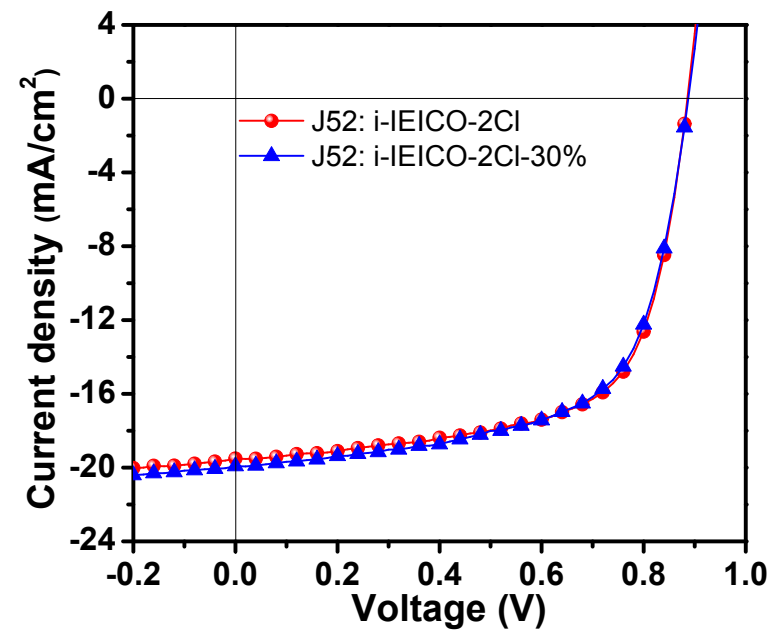

Figure S10. The $J-V$ characteristics of the J52: i-IEICO-2CI and J52: i-IEICO-2Cl-30\% based solar cells. 

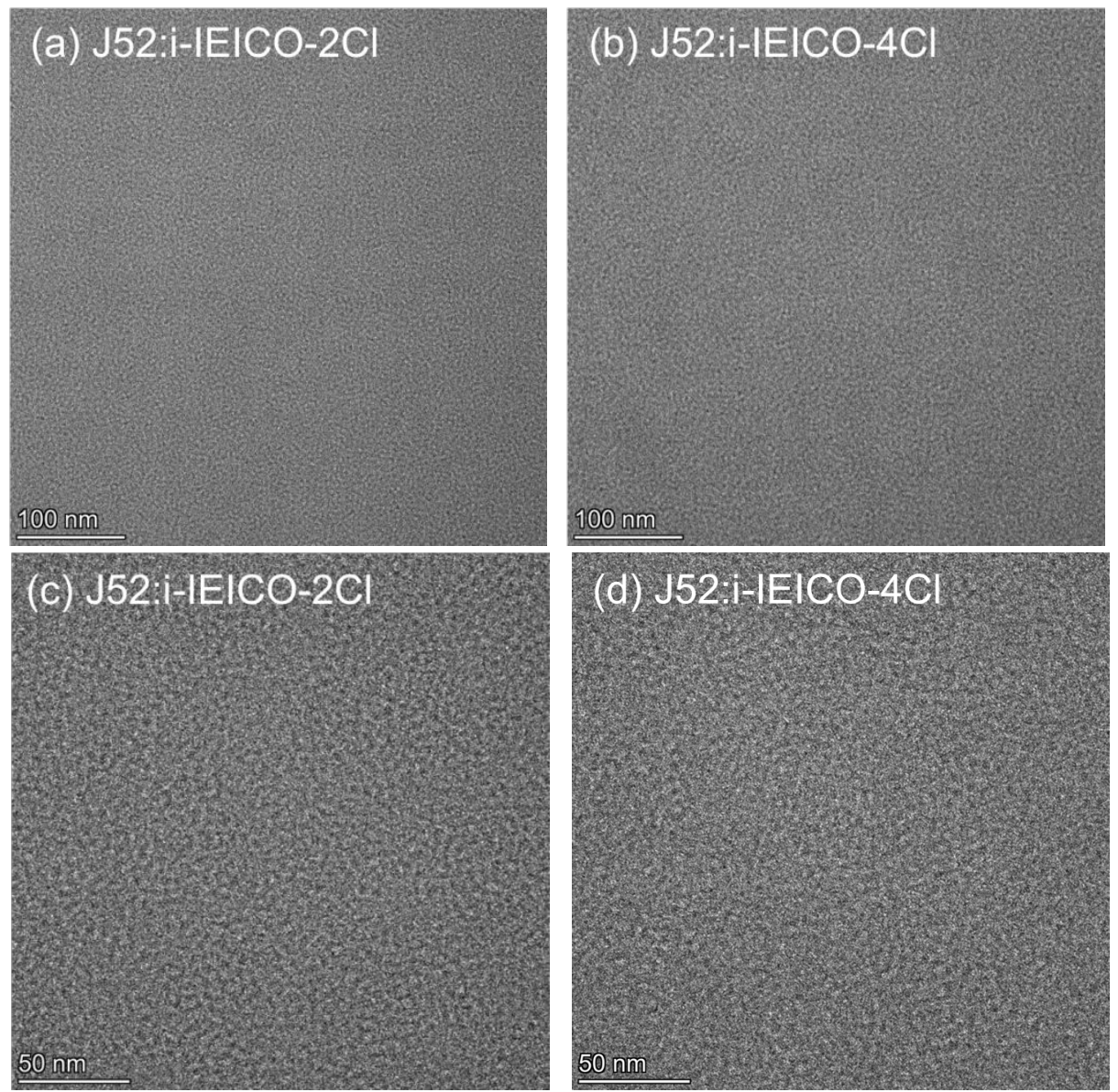

Figure S11. TEM images of J52:i-IEICO-2CI (a and c) and J52:i-IEICO-4CI (b and d) blend films with scale-plates of 100 and $50 \mathrm{~nm}$.

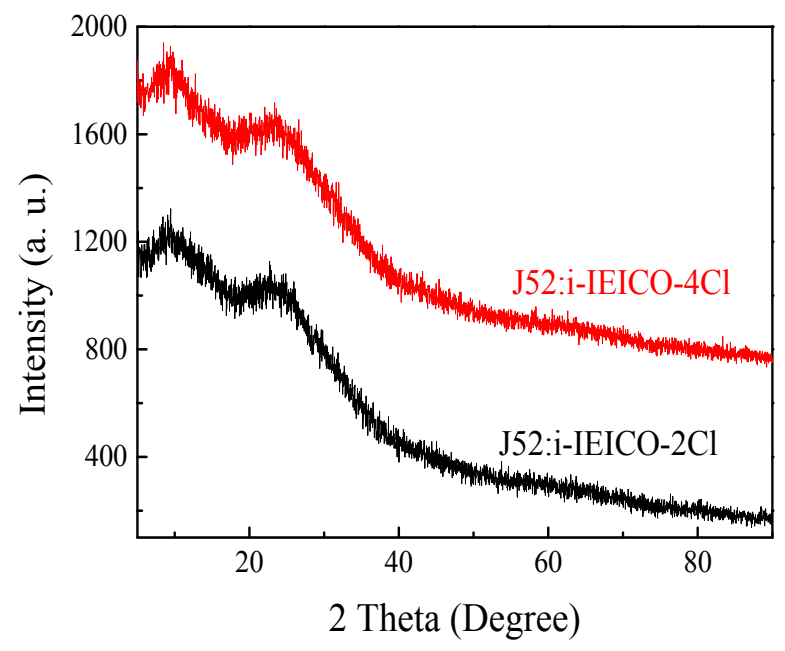

Figure S12. XRD plots of J52:i-IEICO-2CI and J52:i-IEICO-4CI blend films. 
Table S1. Calculations of total energy and their geometries of the four isomers of i-IEICO-Cl4,

i-IEICO-Cl5, and i-IEICO-4Cl.

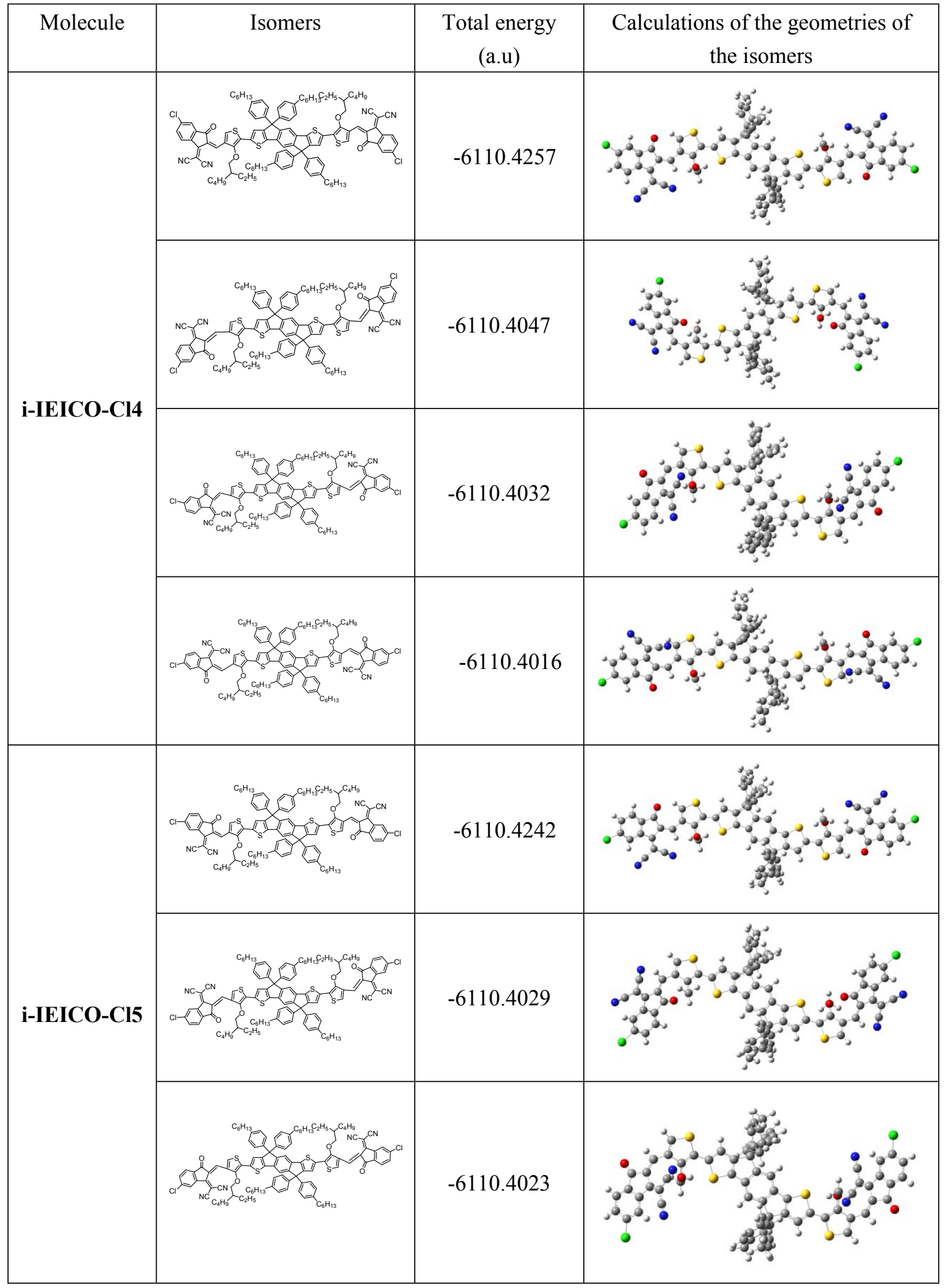




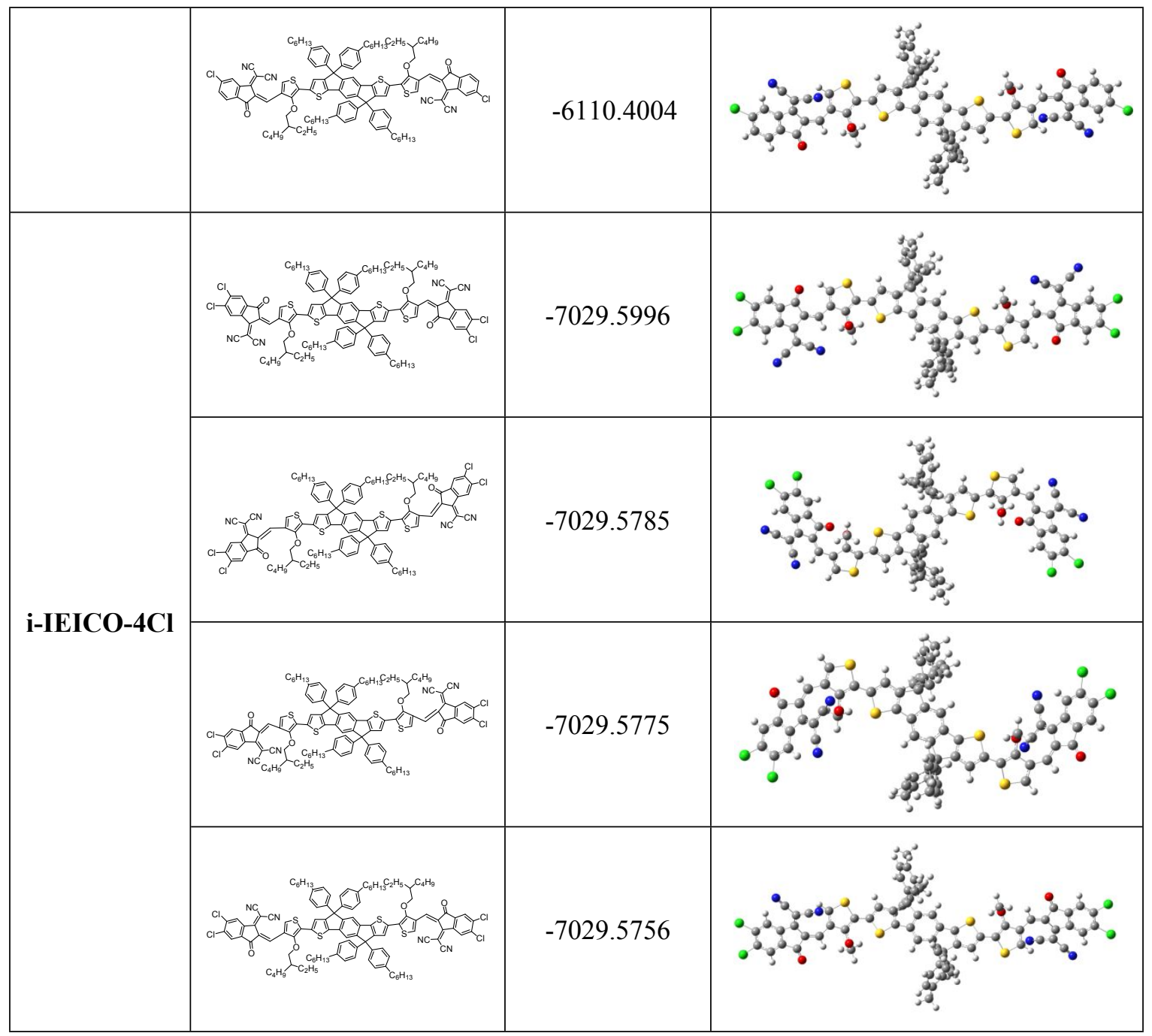

Table S2. Calculated molecular energy levels of three isomers at their optimized geometry from the DFT at B3LYP/6-31G(d,p) level.

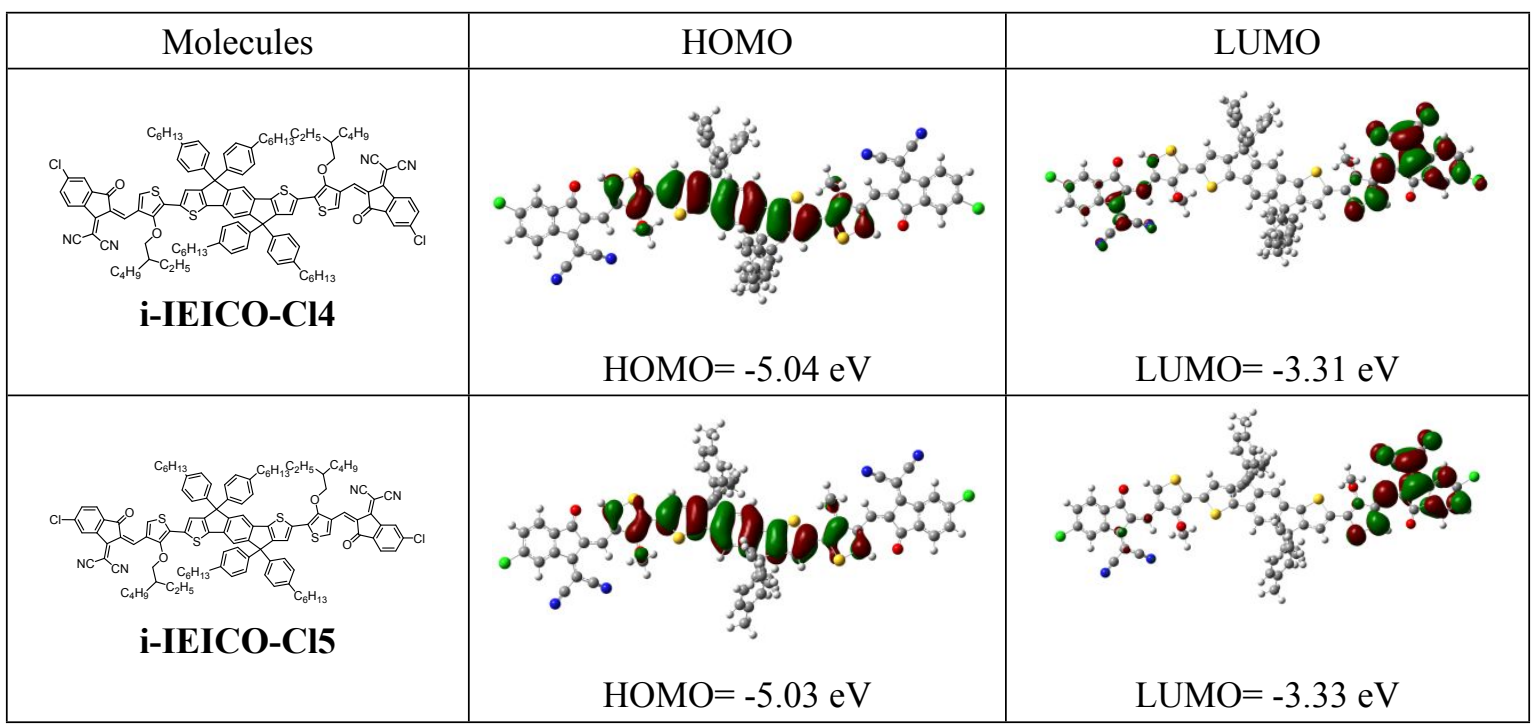




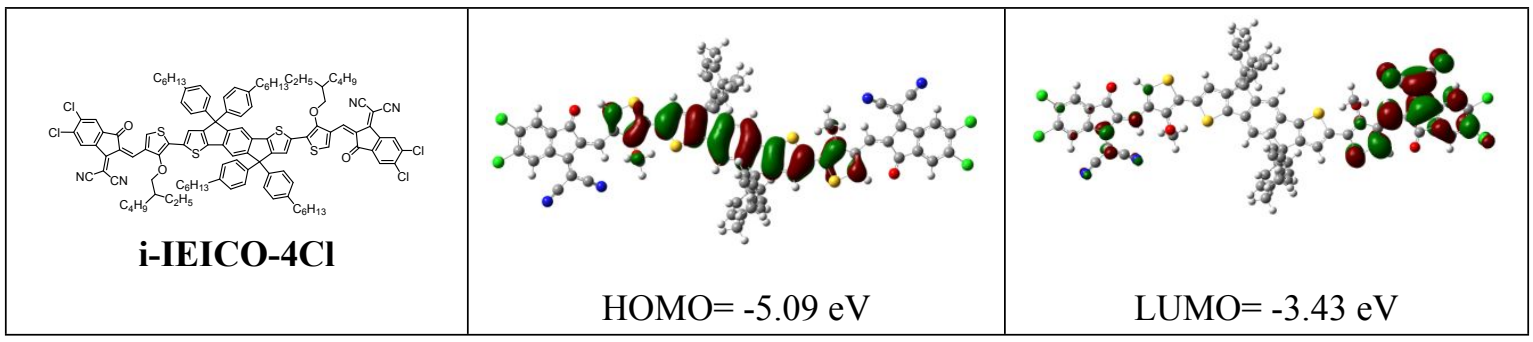

Table S3. Calculated dipole moments of three isomers at their optimized geometry from the DFT at B3LYP/6-31G(d,p) level.

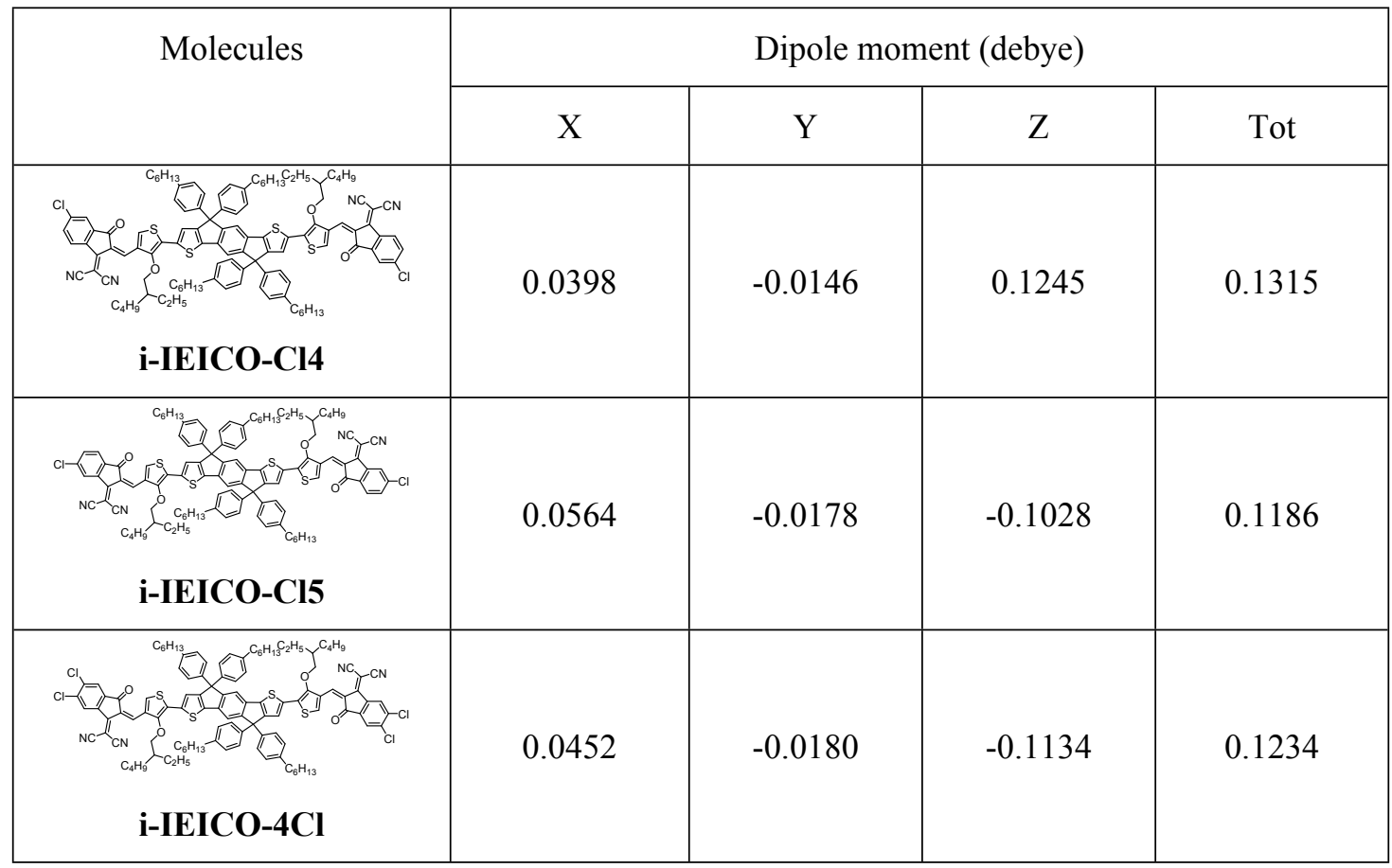

Table S4. Measurement of the hole and electron mobilities.

\begin{tabular}{|c|c|c|c|c|}
\hline Active layer & $\begin{array}{c}\text { Thickness } \\
(\mathrm{nm})\end{array}$ & $\begin{array}{c}\mu_{h} \\
\left(\mathrm{~cm}^{2} \mathrm{~V}^{-1} \mathrm{~s}^{-1}\right)\end{array}$ & $\begin{array}{c}\mu_{e} \\
\left(\mathrm{~cm}^{2} \mathrm{~V}^{-1} \mathrm{~s}^{-1}\right)\end{array}$ & $\mu_{h} / \mu_{e}$ \\
\hline J52:i-IEICO-2Cl & 75 & $1.72 \times 10^{-4}$ & $1.41 \times 10^{-4}$ & 1.22 \\
\hline J52:i-IEICO-4CI & 74 & $2.34 \times 10^{-4}$ & $2.00 \times 10^{-4}$ & 1.17 \\
\hline
\end{tabular}

Table S5. Summary of photovoltaic parameters of the J52:i-IEICO-2Cl-30\%-based devices under simulated AM1.5G illumination $\left(100 \mathrm{~mW} \mathrm{~cm}^{-2}\right)$.

\begin{tabular}{|c|c|c|c|c|}
\hline Active layer & $\begin{array}{c}V_{O C} \text { a),b) } \\
{[\mathrm{V}]}\end{array}$ & $\begin{array}{c}J_{S C} \text { a),b) } \\
{\left[\mathrm{mA} / \mathrm{cm}^{2}\right]}\end{array}$ & $\begin{array}{c}\mathrm{FF}^{\mathrm{a}} \text { ),b) } \\
{[\%]}\end{array}$ & $\begin{array}{c}\text { PCE } \\
{[\%]}\end{array}$ \\
\hline J52:i-IEICO-2Cl-30\% & $\begin{array}{c}0.896 \pm 0.008 \\
(0.887)\end{array}$ & $\begin{array}{c}19.57 \pm 0.31 \\
(19.92)\end{array}$ & $\begin{array}{c}64.1 \pm 0.4 \\
(64.6)\end{array}$ & $\begin{array}{c}11.24 \pm 0.16 \\
(11.42)\end{array}$ \\
\hline
\end{tabular}

a)Calculated from 10 devices; b) The best values are given in parenthesis. 


\section{Reference}

1. Bin, H.; Zhang, Z.-G.; Gao, L.; Chen, S.; Zhong, L.; Xue, L.; Yang, C.; Li, Y. Non-Fullerene Polymer Solar Cells Based on Alkylthio and Fluorine Substituted 2D-Conjugated Polymers Reach 9.5\% Efficiency. J. Am. Chem. Soc., 2016, 138, 4657-4664.

2. Wang, W.; Zhao, B.; Cong, Z.; Xie, Y.; Wu, H.; Liang, Q.; Liu, S.; Liu, F.; Gao, C.; Wu, H.; Cao, Y. Nonfullerene Polymer Solar Cells Based on a Main-Chain Twisted Low-Bandgap Acceptor with Power Conversion Efficiency of 13.2\%. ACS Energy Lett. 2018, 3, 1499-1507.

3. Zhang, M.; Wang, J.; Zhang, F.; Mi, Y.; An, Q.; Wang, W.; Ma, X.; Zhang, J.; Liu, X. Ternary Small Molecule Solar Cells Exhibiting Power Conversion Efficiency of 10.3\%. Nano Energy. 2017, 39, 571-581. 